\title{
Formal and Informal Savings Habits and Income Levels: A Case Study in Mexico
}

\author{
Georgina Manrique Morteo ${ }^{1}$, Milka Escalera-Chávez ${ }^{2} \&$ Elena Moreno-García ${ }^{3}$ \\ ${ }^{1}$ Colegio Jurista, Cuernavaca, Morelos, Mexico \\ ${ }^{2}$ Universidad Autónoma de San Luis Potosí, San Luis Potosí, Mexico \\ ${ }^{3}$ Instituto Tecnológico Superior de Misantla, Veracruz, Mexico \\ Correspondence: Elena Moreno-García, Instituto Tecnológico Superior de Misantla. Km. 1.8 Carretera a, Loma del \\ Cojolite, C.P. 93821, Misantla, Veracruz, México.
}

Received: April 17, 2021

Accepted: May 18, 2021

Online Published: June 10, 2021

doi:10.5430/ijfr.v12n5p1

URL: https://doi.org/10.5430/ijfr.v12n5p1

\begin{abstract}
Saving represents one of the most important determinants of personal success and economic development. However, in developing economies, opportunities for structured and institutionalized savings are rare. The intention of the study is to generate evidence on the type of relationship existing between income levels and formal and informal saving habits of a group of people from three different cities in Mexico. From a non-probabilistic convenience sampling, the data of 260 participants were obtained. A logit model was estimated. The results show that there is a positive relationship between higher income levels and formal saving habits and an inverse relationship between higher income levels and informal saving practices. Although the size of the sample does not allow conclusions to be drawn to the level of generalization, it has allowed the generation of evidence that in future studies can be contrasted with a larger sample.
\end{abstract}

Keywords: habits, income, saving, logit, Mexico

\section{Introduction}

The Organization for Economic Co-operation and Development (OECD) aptly defines financial literacy as not only the knowledge and understanding of financial concepts and risks but also the skills, motivation, and confidence to apply such knowledge and understanding in order to make effective decisions across a range of financial contexts, to improve the financial well-being of individuals (Lusardi, 2019, p. 1)

Increasing the level of financial literacy of the population is a challenge for all countries in the world. In Mexico, the population has basic financial concepts and a limited culture of financial planning and forecasting for the future. This is demonstrated by the results of the 2016 International Survey of Financial Literacy Skills for adults, which reveal that in Mexico, $60 \%$ of the population budgets their expenses, $53 \%$ saved in the twelve months prior to the application of the survey and 54\% of the Mexican adult population set long-term financial goals. In contrast, for the average population of the G20 countries, $60 \%$ budgeted their expenses, $64 \%$ made savings in the twelve months prior to the application of the survey, and $46 \%$ of the adult population of those countries established long-term financial goals (Consejo Nacional de Inclusión Financiera, CONAIF, 2018).

In Mexico, the preference for current consumption obtained the same score as the average of the G20 countries (60 points). It is relevant to note that $64 \%$ of the Mexican population lives from day to day, $52 \%$ prefer to spend today rather than saving for the future, and $68 \%$ believe that money is to be spent. These results are very similar to those obtained by the G20 countries, since 52\% of the population of these countries live from day to day, $57 \%$ prefer to spend today than saving for the future and $71 \%$ believe that money is meant to be spent (CONAIF, 2018).

Similarly, the National Survey of Financial Inclusion (2018) provides evidence on the scarce financial culture in Mexico. $86.6 \%$ of Mexicans reported making unplanned or out-of-budget purchases, $66.8 \%$ asked relatives, friends or acquaintances for a loan and only $29.9 \%$ used their savings to face an economic emergency equal to or greater than their monthly income. $67.3 \%$ prefer to spend the money rather than saving it for the future, $47.1 \%$ have a savings account and $78.5 \%$ of the adult population make some type of savings, whether formal or informal. $15.2 \%$ 
save using formal mechanisms, $31.4 \%$ by informal mechanisms and $31.9 \%$ save in both channels. $42.5 \%$ report that what they earned or received each month was insufficient to cover their expenses.

Financial behavior varies depending on the income level of the population. In general, higher savings rates are associated with the rich and middle income households (Aidoo-Mensah, 2018). García, Grifoni, López and Mejia, (2013) provide evidence that in Latin America and the Caribbean, those with higher incomes have a greater knowledge of financial matters, make formal savings and request loans from financial institutions. While the population with lower incomes carry out informal savings and credit actions and they are more likely not to pay their debts.

Analyzing the relationship that exists between citizens income levels and their type of savings, generates empirical evidence on which financial institutions can base their incentive strategy to include as users to a greater number of people and this way, contributing to increase the levels of financial inclusion of a country.

Based on the above, the following question arises: Is there a statistically significant relationship between the type of savings and the income levels of the population? To answer the research question, evidence of this relationship is generated in a group of working-age adults located in three cities in Mexico: Cuernavaca, the Port of Veracruz and the city of Puebla.

\section{Literature Review}

Barriers to saving exist for many, particularly the world's poor. Despite these barriers, evidence suggests that the poor have substantial (latent) demand for savings (Karlan, Ratan and Zinman, 2014). The literature provides important empirical evidence on the relationship between household savings and the income variable. Iqbal, Hui, Khurshaid, Hafeez and Danish (2018) identified the income level and the area of residence as determinants of household savings in Pakistan. By incrementing income one unit, household savings increase 20\%. Regarding the area of residence, households in urban areas have a greater propensity to save than households in rural areas. Szopinski (2017) identified in Poland that the highest levels of savings were generated at higher levels of income and among families living in large cities.

Goedecke, Guérin, D’Espallier and Venkatasubramanian (2017) comparing informal and formal saving practices of rural households in Southeast India, found that informal saving types are still widespread and much more common devices to save than are bank accounts, especially among the poorest. Yadeta, Bedemo and Belina (2017) examined the factors that affect saving behavior of rural households in region in Ethiopia. They identify that nearly $32 \%$ of households opt for the use informal saving options owning to lack of awareness about the use of formal institutions, low annual income and distance of the institutions away from their residence.

The study by Mosquera (2017) in Spanish households analyzes the evolution of the savings rate in the 1985-2016 period, in line with the life cycle and permanent income model. Social benefits, the dependency rate by stage in the life cycle, unemployment and credit, and to a lesser extent permanent income and wealth are established as long-term structural determinants of the gross saving rate.

In Colombia, Iregui-Bohórquez, Melo-Becerra and Ramírez-Giraldo (2018) analyze the determinants of saving by low and middle-income individuals in urban and rural areas, finding low levels of savings in general, 18\% in urban areas and 13\% in rural areas. Within both groups, a greater probability of saving was observed among people aged 15 and 47, a positive relationship between educational levels and a greater probability of saving in urban areas, in people located in the upper income quintiles, and in rural areas, only among people who are located in the highest income quintile. Additionally, the empirical results indicate that, in Colombian households, education and income increase the probability of making formal savings, observing a greater tendency to informal saving by individuals residing in rural areas $(82 \%)$ in relation to those living in urban areas $(50 \%)$.

Empirical studies on saving in Mexican households have identified as determinants: income level, formality of employment, access to health services, access to credit and household structure according to age (Valles and Aguilar , 2015), as well as the differential in the marginal propensity to consume according to income level (Nava and Brown, 2018). In addition, the absence of educational training is shown in the lack of personal vision about the future, coupled with income restrictions (Rivera and Nava, 2012); and the relationship between the level of income and the type of saving habits (Di Giannatale, Elbitar, Maya, Ramírez and Roa, 2010).

The study carried out in Mexico by Di Giannatale, Elbitar, Maya, Ramírez and Roa (2010) to employees of an academic institution with at least basic education, indicates that $51 \%$ make formal savings, with a greater participation of those who have a level of high income in relation to the low income group. Among those who do not 
make formal savings, the main factors are the lack of money to save or the lack of confidence. Regarding the use of informal instruments to save (group savings), it is predominant in low-income employees.

From the theoretical review and empirical evidence, the following research hypothesis is formulated: There is a statistically significant relationship between formal and informal saving habits and the income levels of the population. To verify the assumption made, the following objective is established: to demonstrate if there is a statistically significant relationship between the habit of formal and informal saving and the level of income.

\section{Methodology}

The type of study is quantitative, explanatory and cross-sectioned. The research basically made use of primary data that were obtained through the application of 385 surveys, of which 125 were discarded for being incomplete. This provided the researchers with information from 260 people to achieve the research goal. The surveys were applied in the March-May 2019 period from a non-probabilistic convenience sampling, to people over 18 years of age, located in three different cities in Mexico: Cuernavaca in the state of Morelos, the Port of Veracruz and the city of Puebla.

For the application of the instrument, some contacts helped to carry out the survey with visits to the workplace or homes of the people who agreed to participate. The instrument used to collect the data was taken from the National Survey of Financial Inclusion (ENIF, 2018). The study variables are presented below:

Income levels (Y), defined from the National Occupation and Employment Survey (ENOE, 2019): high, more than 30 thousand pesos; medium high, between 20 and 30 thousand pesos; medium, between 10,000 and 19,999 pesos; medium low, between 5,000 and 9,999 pesos; low, less than 5,000 pesos.

Saving habits (HA): Savings made in the immediately preceding year, where $1=$ saved and $0=$ did not save.

According to Adday, Gyamfi and Boadi (2017), several models have been used in previous research to estimate parameters of binary dependent variables, of which probit and logit models have been identified in the literature as the most appropriate models for this analysis and therefore have been widely used by researchers (Adeogun, Ajana, Ayinla, Yarhere and Adeogun, 2001; Awunyo-Vitor, 2012). The probit and logit models are similar and produce similar results, and the choice depends on which one is convenient for the researcher (Johnston and DiNardo, 1997).

In this research, descriptive statistics and the development of a logit model were used for data analysis. Specifically, the description of the socioeconomic characteristics of the participants and their savings mechanisms are presented from the use of tables, frequencies and percentages.

\subsection{Model Description}

A Logit model is developed from the establishment of a dichotomous dependent variable (Pucutay, 2002, pp. 22-23), where 1 indicates if the subject has savings habits. The different income levels are established as independent variables. Then, the model would be expressed as follows:

$$
P_{i}=E\left(Y=1 \mid Z_{i}\right)=\frac{1}{1+e^{-Z_{i}}}
$$

Where $\mathrm{Zi}$ is the set of exogenous variables and parameters $\left(\alpha_{0}+\alpha_{1} Y_{i}\right) . Y_{i}$ is the endogenous variable that represents saving habits and can be formal saving habits (HAF) and informal saving habits (HAI) and i represents the individual surveyed. The exogenous variables are income levels and $\alpha_{0}, \alpha_{1},, \alpha_{n}$ represent the parameters associated with the exogenous variables. The matrix of the set of exogenous variables of the variable $H A_{i}$, composed of:

$\mathrm{X}=$ High income level $\left(Y A_{i}\right)$, Upper middle income level $\left(Y M A_{i}\right)$, Middle income level $\left(Y M_{i}\right)$, Lower middle income level $\left(Y M B_{i}\right)$ and low income $\left(Y B_{i}\right)$.

In such a way that the probability that the subject performs $H A_{i}$, is given by:

$$
P[Y=1]=F(X, \beta)=\frac{1}{1+e^{-Z_{i}}}
$$

And if $H A_{i}$ is not performed, it will be

$$
P[Y=0]=1-F(X, \beta)=\frac{1}{1+e^{Z_{i}}}
$$

Where $\mathrm{X}$ represents the exogenous variables corresponding to the different income levels (YA, YMA, YM, YMB and $\mathrm{YB}$ ) and $\beta$ the parameters. So the odds ratio in favor of saving habits is:

$$
\frac{P[Y=1]}{1-P[Y=1]}=\frac{F(X, \beta)}{1-F(X, \beta)}=\frac{\frac{1}{1+e^{-Z_{i}}}}{\frac{1}{1+e^{Z_{i}}}}=\frac{1+e^{Z_{i}}}{1+e^{-Z_{i}}}=e^{Z_{i}}=e^{\left(\alpha_{0}+\alpha_{1} Y A_{i}+\alpha_{2} Y M A_{i}+\alpha_{3} Y M_{i}+\alpha_{4} Y M B_{i}+\alpha_{5} Y B_{i}\right)}
$$


Finally, logarithms are taken from the previous equation and the following model is proposed to estimate:

$$
\operatorname{Ln}\left(\frac{P_{i}}{1-P_{i}}\right)=\alpha_{0}+\alpha_{1} Y A_{i}+\alpha_{2} Y M A_{i}+\alpha_{3} Y M_{i}+\alpha_{4} Y M B_{i}+\alpha_{5} Y B_{i}+u_{i}
$$

where the variables mean the same thing and $u_{i}$ is the stochastic disturbance that follows a normal distribution with

$$
\mu=0 \text { y } \sigma^{2}=\frac{1}{N_{i} P_{i}\left(1-P_{i}\right)} \text {. }
$$

The estimates were made with the statistical software Stata 14.

\section{Results}

Table 1 shows the sociodemographic characteristics of the sample.

\begin{tabular}{|c|c|c|c|c|c|}
\hline \multicolumn{2}{|l|}{ Gender (\%) } & \multicolumn{2}{|l|}{ Children (\%) } & \multicolumn{2}{|c|}{ Work $(\%)$} \\
\hline Male & Female & With children & Without children & Active & Unemployed \\
\hline 73.5 & 26.5 & 37.7 & 62.3 & 98.1 & 1.9 \\
\hline \multicolumn{2}{|c|}{ Marital status (\%) } & \multicolumn{4}{|c|}{ Social security institution (\%) } \\
\hline Common law & 19.6 & IMSS & & 84.2 & \\
\hline Separated & 3.1 & ISSSTE & & 6.2 & \\
\hline Divorced & 1.9 & PEMEX, SED & NA OR SEMAR & 0.4 & \\
\hline Widowed & 0.8 & Private medica & insurance & 1.9 & \\
\hline Married & 39.2 & No medical se & ice & 5.8 & \\
\hline Single & 35.4 & Doesn't know & & 1.5 & \\
\hline \multicolumn{6}{|l|}{ Schooling } \\
\hline \multicolumn{4}{|c|}{ Middle school or technical studies with middle school } & \multicolumn{2}{|l|}{4.6} \\
\hline \multicolumn{4}{|c|}{ High school or technical studies with high school } & \multicolumn{2}{|l|}{40.8} \\
\hline \multicolumn{4}{|c|}{ Degree (undergraduate) } & \multicolumn{2}{|l|}{24.6} \\
\hline \multicolumn{4}{|c|}{ Master's degree } & \multicolumn{2}{|l|}{28.8} \\
\hline \multicolumn{4}{|l|}{ Doctorate } & \multicolumn{2}{|l|}{1.2} \\
\hline
\end{tabular}

Table 1. Sociodemographic characteristics of the sample

Source: own.

There is a high percentage of men $(73.5 \%)$ in the sample. It is also observed that the majority of the participants do not have children $(62.3 \%)$ and a high percentage is working $(98.1 \%)$. The schooling of the participants stands out, the vast majority has at least high school or technical studies with high school and a high percentage $(84.2 \%)$ have access to a social security institution. Table 2 presents the income levels of the sample and their saving habits.

Table 2. Income levels and formal and informal saving habits of sample

\begin{tabular}{llll}
\hline Variable & Description & Absolute frequency & Relative frequency \\
\hline Income levels & Low. Less than 5 thousand pesos & 46 & $17.7 \%$ \\
\cline { 2 - 4 } (net monthly) & Lower middle. 5 to 10 thousand pesos & 93 & $35.8 \%$ \\
\cline { 2 - 4 } & Middle. 10 to 20 thousand pesos & 84 & $32.3 \%$ \\
\cline { 2 - 4 } & Upper middle. 20 to 30 thousand pesos & 22 & $8.4 \%$ \\
\cline { 2 - 4 } & High. More than 30 thousand pesos & 15 & $5.8 \%$ \\
\hline Saving habits & Formal & 54 & $20.8 \%$ \\
\hline
\end{tabular}




\begin{tabular}{lll}
\hline Informal & 73 & $28.1 \%$ \\
\hline Both & 67 & $25.8 \%$ \\
Without savings & 66 & $25.3 \%$ \\
\hline
\end{tabular}

Source: own

Table 3 shows that the income level of the majority of the participants $(68.1 \%)$ is in the range of net monthly salaries between 5 and 20 thousand pesos. Regarding saving habits, it is observed that one in two people saves, through formal or informal mechanisms, $46.5 \%$ show formal saving habits, when saving money in the last year through a bank account or financial institution, and $53.8 \%$ saved informally by keeping money at home.

When disaggregating the statistics of saving habits, $74.6 \%$ made savings, either through the formal or informal mechanisms or both; $20.8 \%$ made formal savings, $28.1 \%$ informal savings, and $25.8 \%$ used both mechanisms. Table 3 shows the correlation coefficients between the level of income and the different possibilities of saving habits in the sample.

Table 3. Correlation Coefficient Matrix

\begin{tabular}{|c|c|c|c|c|c|c|c|c|}
\hline Variable & YA & YMA & YM & YMB & YB & HAF & HAI & HAIF \\
\hline YA & 1.00 & & & & & & & \\
\hline YMA & -0.08 & 1.00 & & & & & & \\
\hline YM & $-0.17 * * *$ & $-0.21 * * *$ & 1.00 & & & & & \\
\hline YMB & $-0.18 * * *$ & $-0.23 * * *$ & $-0.52 * * *$ & 1.00 & & & & \\
\hline YB & $-0.11 *$ & $-0.14 * *$ & $-0.32 * * *$ & $-0.35 * * *$ & 1.00 & & & \\
\hline HAF & $0.20 * * *$ & $0.12 *$ & 0.09 & $-0.11 * *$ & $-0.19 * * *$ & 1.00 & & \\
\hline HAI & $-0.15 * *$ & $-0.13 * *$ & 0.01 & 0.00 & $0.18 * * *$ & $-0.32 * * *$ & 1.00 & \\
\hline HAIF & 0.01 & 0.07 & -0.05 & 0.04 & -0.04 & $-0.30 * * *$ & $-0.37 * * *$ & 1.00 \\
\hline \multicolumn{9}{|c|}{$* * *$ and $* * *$ show significance at $10 \%, 5 \%$ y $1 \%$ respectively } \\
\hline
\end{tabular}

Source: own

Table 3 shows that the correlation between formal saving habits and high, medium-high and medium income is positive, although with different levels of significance. In contrast, for people with low incomes, the relationship with formal saving habits is negative. Regarding the correlation between high and upper middle income levels and informal saving habits, it is negative and in relation to low income it is positive. Finally, no statistical significance is observed between the different income levels and saving habits by both mechanisms.

Table 4 shows the estimates of the model coefficients $(\alpha)$, the Z-test statistic and the significance. In the equation, the variable HAI $i$ is equal to 1 when the person saves informally and zero when the person do not save.

Table 4. Coefficients, significance and odds ratio of informal saving habits and income levels

\begin{tabular}{llllll}
\hline HAI & Coef. & Std. Err. & Z & P>Z & Odds Ratio \\
\hline YA & -1.737538 & 0.6631996 & -2.62 & 0.009 & 0.175953 \\
\hline YMA & -0.908258 & 0.5312796 & -1.71 & 0.087 & 0.403225 \\
\hline YM & -0.678309 & 0.3828456 & -1.77 & 0.076 & 0.507474 \\
\hline YMB & $0-.488265$ & 0.3775523 & -1.29 & 0.196 & 0.61369 \\
\hline YB & 0 & (omitted) & & & 1 \\
\hline _cons & 0.725937 & 0.314523 & 2.31 & 0.021 & 2.066667
\end{tabular}

Source: own 
It is observed that the high income level is the only variable that has a value greater than $\pm 1.96(-2.62)$ at a level of $95 \%$, it is also the only one that the critical level is less than $0.05(0.009)$. Therefore, the null hypothesis is rejected and it is stated that the independent variable (high income level) is significantly related to the dependent variable (saving level). The coefficient of this variable -high income- is negative (-1.737538) and its odds value is less than 1 (0.175953), which indicates that people with higher incomes tend not to save informally. The model obtained in the study is:

$$
P(Y=1)=\frac{1}{1+e^{-(0.725937+-1.737538 X)}}
$$

From this model, the predicted probabilities for the categories of informal saving habits (1) and high income (1) are calculated:

$$
\begin{gathered}
P(Y=1 / X=1)=\frac{1}{1+e^{-(0.725937-1.737538 * 1)}} \\
P(Y=1 / X=1)=.26666
\end{gathered}
$$

That is, there is a probability of .266 that people with high incomes will save informally.

Table 5 shows the classification table, also called the confusion matrix or the correct classification matrix. It is an indicator of the validity of the model, because it shows the predictive capabilities. The rows of the table contain the categories of the dependent variable to which the cases actually belong, while the columns contain the predicted categories. It is observed that, of the 260 people, 126 have informal saving habits and 130 do not have saving habits. The indicators to evaluate the discriminatory capacity of the predictive model are shown in the table.

Table 5. Correctly classified matrix

\begin{tabular}{llll}
\hline \multicolumn{1}{c}{ True } & & \\
\hline Classified & $\mathrm{D}$ & $\mathrm{D}$ & Total \\
\hline+ & 126 & 97 & 223 \\
\hline- & 14 & 23 & 37 \\
\hline Total & 140 & 120 & 260 \\
\hline Classified + if predicted $\operatorname{Pr}(\mathrm{D})>=.5$ & & \\
\hline True D defined as HAT $!=0$ & $\operatorname{Pr}(+\mid \mathrm{D})$ & $90.00 \%$ \\
\hline Sensitivity & $\operatorname{Pr}(-\mid \sim \mathrm{D})$ & $19.17 \%$ \\
\hline Specificity & $\operatorname{Pr}(\mathrm{D} \mid+)$ & $56.50 \%$ \\
\hline Positive predictive value & $\operatorname{Pr}(\sim \mathrm{D} \mid-)$ & $62.16 \%$ \\
\hline Negative predictive value & & $80.83 \%$ \\
\hline False + rate for true $\sim \mathrm{D}$ & $\operatorname{Pr}(+\mid \sim \mathrm{D})$ & $10.00 \%$ \\
\hline False - rate for true D & $\operatorname{Pr}(-\mid \mathrm{D})$ & $43.50 \%$ \\
\hline False + rate for classified + & $\operatorname{Pr}(\sim \mathrm{D} \mid+)$ & $37.84 \%$ \\
\hline False - rate for classified - & $\operatorname{Pr}(\mathrm{D} \mid-)$ & $57.31 \%$ \\
\hline Correctly classified & & \\
\hline
\end{tabular}

Source: own 
The true positive rate (sensitivity) is $90 \%$. This measure assesses whether the high-income person saves informally. The true negative rate (specificity) of $19.17 \%$ assesses whether the person with high income does not save in informal mechanisms. In addition, a positive predictive value of $56.50 \%$ and a negative predictive value of $62.16 \%$ are shown, with a validity index of $57.31 \%$, that is, the model has predictive capacity with the variables included in the model.

Table 6 presents the estimates of the model coefficients $(\alpha)$. In the equation, the HAF variable is equal to 1 when the person saves in formal mechanisms and zero when the person does not save.

Table 6. Coefficients, significance and odds ratio of formal saving habits and income levels

\begin{tabular}{llllll}
\hline$H A F$ & $\alpha_{\mathrm{n}}$ & $\sigma$ & $\mathrm{Z}$ & $\mathrm{P}>\mathrm{Z}$ & Odds Ratio \\
\hline$Y A$ & 2.4277 & 0.7276 & $3.34^{*}$ & 0.001 & 11.33333 \\
\hline$Y M A$ & 2.0222 & 0.5847 & $3.46^{*}$ & 0.001 & 7.555554 \\
\hline$Y M$ & 0.9938 & 0.4004 & $2.48^{* *}$ & 0.013 & 2.70155 \\
\hline$Y M B$ & 0.7600 & 0.3957 & $1.92^{* * *}$ & 0.055 & 2.138365 \\
\hline$Y B$ & 0 & (omitted $)$ & & & 0.132353 \\
\hline$C$ & -1.0414 & 0.3357 & $-3.10^{*}$ & 0.002 & .3529412 \\
\hline
\end{tabular}

Source: own

It is noted that none of the variables has a negative sign and that three of them YA, YMA, YM, their Z value is greater than \pm 1.96 , at a level of $95 \%$. Results also show that the critical level is less than 0.05 . Therefore, the null hypothesis is rejected and it is confirmed that the independent variables YA, YMA, YM are significantly related to the dependent variable (formal saving habits). The coefficient of each of the significant variables is positive and the odds value is greater than 1, this reveals that people who are in the lower middle income level (between 5 and 9,999 thousand pesos) and low (less than 5 thousand pesos ) tend not to save.

The model obtained in the study is:

$$
\begin{array}{r}
\mathrm{P}(\mathrm{Y}=1)=\frac{1}{1+\mathrm{e}^{-(-1.0414+2.4277 * 1+2.0222 * 1+0.9938 * 1)}} \\
\mathrm{P}(\mathrm{Y}=1 / \mathrm{X}=1)=.0 .987900326
\end{array}
$$

This means that there is a probability of 0.987 that people with incomes greater than 10,000 pesos will save formally.

Table 7 shows the correct classification matrix for formal saving habits. It is observed that, of the 260 people, 28 have formal saving habits and 130 do not have formal saving habits. The indicators to evaluate the discriminatory capacity of the predictive model of saving habits are shown in the table.

Table 7. Correctly classified matrix

\begin{tabular}{llll}
\hline \multicolumn{4}{c}{ True } \\
\hline Classified & $\mathrm{D}$ & $-\mathrm{D}$ & Total \\
\hline+ & 28 & 9 & 37 \\
\hline- & 93 & 130 & 223 \\
\hline Total & 121 & 139 & 260 \\
\hline Classified + if predicted $\operatorname{Pr}(\mathrm{D})>=.5$ & & \\
\hline True D defined as HAF $!=0$ & & $23.14 \%$ \\
\hline Sensitivity & $\operatorname{Pr}(+\mid \mathrm{D})$ & $93.53 \%$ \\
\hline Specificity & $\operatorname{Pr}(-\mid \sim \mathrm{D})$ & $75.68 \%$ \\
\hline Positive predictive value & $\operatorname{Pr}(\mathrm{D} \mid+)$ & $58.30 \%$ \\
\hline Negative predictive value & $\operatorname{Pr}(\sim \mathrm{D} \mid-)$ & \\
\hline
\end{tabular}




\begin{tabular}{lll}
\hline False + rate for true $\sim \mathrm{D}$ & $\operatorname{Pr}(+\mid \sim \mathrm{D})$ & $6.47 \%$ \\
\hline False - rate for true D & $\operatorname{Pr}(-\mid \mathrm{D})$ & $76.86 \%$ \\
\hline False + rate for classified + & $\operatorname{Pr}(\sim \mathrm{D} \mid+)$ & $24.32 \%$ \\
\hline False - rate for classified - & $\operatorname{Pr}(\mathrm{D} \mid-)$ & $41.70 \%$ \\
\hline & & \\
\hline Correctly classified & & $60.77 \%$ \\
\hline
\end{tabular}

Source: own

The rate of true positives (sensitivity) is $23.14 \%$, this measure evaluates if the person with an income greater than 10,000 pesos saves in formal mechanisms. The rate of true negatives (specificity) is $93.53 \%$, assesses whether the person, with an income greater than 10,000 pesos, does not save in formal mechanisms. In addition, a positive predictive value of $75.68 \%$ and a negative predictive value of $58.30 \%$ are shown, with a validity index of $60.77 \%$. In other words, the model has the predictive power with the variables included in the model.

\section{Conclusions}

The study carried out confirms the positive relationship between higher levels of income and formal saving habits and the inverse relationship between higher levels of income and informal saving practices, coinciding with Di Giannatale et. al. (2010), Rivera and Nava (2012), Valles and Aguilar (2015), Goedecke et. al. (2017) and Yadeta et. al. (2017).

The study shows that the academic level of the participants is higher than the national average and that three out of four make some type of savings, with a greater incidence in formal mechanisms than the national average, 20.8\% compared to $15.2 \%$. This coincides with Rey, Fernández and Vivel (2015), Morgan and Trinh (2019) and Iregui-Bohórquez et. al. (2018), which show a positive relationship between schooling and saving habits of the population.

It is worth mentioning that the size of the sample limited the possibility of bringing the results to the level of generalization. However, it was sufficient to achieve the objective of the research in the population studied, allowing the generation of evidence about the statistically significant relationship that exists between the formal and informal saving habits of people and their income levels.

In this way, the possibility of continuing the line of research is opened, from the application of the instrument that was used for this analysis, to a larger and more representative sample of a region in Mexico. Another possibility is to expand the study from an analysis by gender. Considering that the sample was made up of a high percentage of men (73.5\%), it becomes interesting to focus the analysis on women to have the possibility of contrasting the results. Additionally, there is an opportunity to discuss the institutional mechanisms that promote formal savings, as well as to develop studies about the effect of educational interventions in the workplace in order to reinforce the quality of financial decision-making.

\section{References}

Adday, B., Gyamfi, A., \& Boadi. (2017). Savings habit among individuals in the informal sector: a case study of gbegbeyishie fishing community in Ghana. International Journal of Economics and Finance, 9(4), 262-272. https://doi.org/10.5539/ijef.v9n4p262

Adeogun, O. A., Ajana, A. M., Ayinla, O. A., Yarhere, M. T., \& Adeogun, M. O. (2001). Application of logit model in adoption decision: a study by hybrid clarias state, Nigeria. American Eursian Journal of Agriculture \& Environmental Science, 4(4), 486-472.

Awunyo-Vitor, D. (2012). Determinants of loan default among farmers in Ghana. Journal of Development and Agricultural Economics, 4(13), 339-345.

Consejo Nacional de Inclusión Financiera, CONAIF. (2018). Reporte nacional de inclusión financiera 2018.

Di Giannatale, S., Elbitar, A., Maya, L., Ramírez, A., \& Roa, M. J. (2010). Confianza, redes sociales y hábitos financieros. Documentos de Trabajo del CIDE, 498. 
Encuesta Nacional de Inclusión Financiera, ENIF. (2018). México. Inclusión financiera: Principales Hallazgos Nacionales y regionales.

Encuesta Nacional de Ocupación y Empleo, ENOE. (2019). Indicadores Trimestrales (15 años y más). Principales indicadores de Ocupación y Empleo, Nacional.

García, N., Grifoni, A., López, J. C., \& Mejía, D. M. (2013). La educación financiera en América Latina y el Caribe. Situación actual y perspectivas. Serie Políticas Públicas y Transformación Productiva 12. Banco de Desarrollo de América Latina.

Goedecke, J., Guérin, I., D’Espallier, B., \& Venkatasubramanian, G. (2017). Why do financial inclusion policies fail in mobilizing savings from the poor? Lessons from rural south India. Development Policy Review, 36, O201-O219. https://doi.org/10.1111/dpr.12272

Iqbal, K., Hui, P., Khurshaid, H. M., \& Danish. (2018). Microeconomics Determinants of Household Savings in Rural and Urban Areas: Evidence from Pakistan. Conference: 2018 International Conference on Management and Operations Research (ICMOR), Beijing ChinaAt: Beijing, China

Iregui-Bohórquez, A. M., Melo-Becerra, L. A., \& Ramírez-Giraldo, M. T. (2018). Factores determinantes del ahorro formal e informal en Colombia. Decisiones financieras de los hogares e inclusión financiera: evidencia para América Latina y el Caribe. Centro de Estudios Monetarios Latinoamericanos (CEMLA), 1, 101-113.

Johnston, J., \& DiNardo, J. (1997). Econometric methods. New York: McGraw Hill.

Karlan, D., Ratan, A., \& Zinman, J. (2014). Savings by and for the poor: a research reviewand agenda. Review of Income and Wealth Series, 60(1), 36-78. https://doi.org/10.1111/roiw.12101

Lusardi, A. (2019). Financial literacy and the need for financial education: evidence and implications. Swiss Journal of Economics and Statistics, 155(1), 1. https://doi.org/10.1186/s41937-019-0027-5

Mensah, A. (2018). Savings and income relationships among households: a review of the literature. Agricultural Socio-Economics Journal, 18(3), 133-143. https://doi.org/10.21776/ub.agrise.2018.018.3.6

Morgan, P., \& Trinh, L. (2019). Determinants and impacts of financial literacy in Cambodia and Viet Nam. Journal of Risk and Financial Management, 12(19). https://doi.org/10.3390/jrfm12010019

Mosquera, A. (2017). Los determinantes a largo plazo y su contribución a la tasa de ahorro de los hogares españoles en el periodo 1985-2016. Revista de Métodos Cuantitativos para la Economía y la Empresa, 24, 292-339.

Nava, I., \& Brown, F. (2018). Determinantes del ahorro de los hogares en México: un análisis de regresión cuantílica. Economía Teoría y Práctica. Nueva Época, 49, 93-118.

Pucutay, V. (2002). Los modelos Logit y Probit en la investigación social: el caso de la pobreza del Perú en el año 2001. Investigaciones INEI-CIDE.

Rey, L., Fernández, S., \& Vivel, M. (2015). La participación de los hogares españoles en planes de pensiones: análisis de sus determinantes. Revista Nacional de Administración, 6(2), 55-75. https://doi.org/10.22458/rna.v6i2.785

Rivera, F., \& Nava. (2012). El sistema de ahorro para el retiro y la cultura de la previsión en México. Ciencia UANL, 15(57), 33-38.

Szopinski, T. (2017). The determinants of household savings in Poland. Acta Scientiarum Polonorum - Oeconomia, 16(2), 117-125. https://doi.org/10.22630/ASPE.2017.16.2.24

Valles, Y., \& Aguilar, A. (2015). El ahorro en México: Evidencia en hogares. Estudios Económicos CNBV, (3), 41-72.

Yadeta, B., Bedemo, A., \& Belina, M. (2017). Determinants of Saving Behavior of Farm Households in Rural Ethiopia: The Double Hurdle Approach. Developing Country Studies, 7(12).

\section{Copyrights}

Copyright for this article is retained by the author(s), with first publication rights granted to the journal.

This is an open-access article distributed under the terms and conditions of the Creative Commons Attribution license (http://creativecommons.org/licenses/by/4.0/). 